\title{
The inhibitory effects of deep-sea water on doxorubicin-induced epithelial-mesenchymal transition
}

\author{
SO-YOUNG CHUN* ${ }^{*}$, SOYOUNG KIM* ${ }^{*}$ and KYUNG-SOO NAM \\ Department of Pharmacology, School of Medicine and Intractable Disease Research Center, \\ Dongguk University, 123 Dongdae-ro, Gyeongju-si 38066, Republic of Korea \\ Received February 13, 2017; Accepted May 31, 2017
}

DOI: $10.3892 /$ or.2017.5726

\begin{abstract}
It has been revealed that the induction of epithelial-mesenchymal transition (EMT) is associated with drug resistance, leading to tumor recurrence and metastasis. Recent studies have shown that chemotherapeutic agents, besides their therapeutic effects, can induce EMT and enhance invasive and metastatic properties of tumor cells. Previously, we revealed that deep-sea water (DSW) exhibited antimetastatic effects in several human cancer cell lines. In the present study, we investigated the effects of DSW on doxorubicin-induced EMT in MCF-7 human breast cancer cells. When treated with doxorubicin, MCF-7 cells displayed characteristics of EMT, such as, mesenchymal markers (vimentin and fibronectin) and EMT-related transcription factors (Slug and Snail-1) in their RNA expression. However, DSW efficiently inhibited doxorubicin-induced EMT, revealing the decreased expression of vimentin, fibronectin, Slug and Snail-1. Moreover, treatment of MCF-7 cells with DSW significantly suppressed their increased migratory ability by doxorubicin as determined by wound-healing assay. We further demonstrated that the inhibitory effects of DSW on doxorubicin-induced EMT appeared to be mediated by inhibition of the ERK1/2, p38 MAPK and PI3K/AKT signaling pathways. Collectively, our data revealed
\end{abstract}

Correspondence to: Professor Kyung-Soo Nam, Department of Pharmacology, School of Medicine and Intractable Disease Research Center, Dongguk University, 123 Dongdae-ro, Gyeongju-si, Gyeongsangbuk-do 38066, Republic of Korea

E-mail: namks@dongguk.ac.kr

*Contributed equally

Abbreviations: DSW, deep-sea water; DOX, doxorubicin, EMT, epithelial-mesenchymal transition; TGF- $\beta$, transforming growth factor- $\beta$; TGF- $\beta$ R, TGF- $\beta$ receptor; ERK1/2, extracellular signal-regulated kinase $1 / 2$; AKT, protein kinase B; FZD, frizzled; LRP 5/6, low-density lipoprotein receptor-related protein 5/6; MAPK, mitogen-activated protein kinase; GAPDH, glyceraldehyde-3phosphate dehydrogenase; MDR1, multidrug resistance protein 1

Key words: deep-sea water, doxorubicin, epithelial-mesenchymal transition, MCF-7 human breast cancer cells that DSW has the potential to abolish undesired side-effects of doxorubicin by targeting EMT.

\section{Introduction}

Chemotherapy is the systemic administration of drugs (singly or in combination) to destroy cancer cells. Although chemotherapy has long been used to treat cancer patients, it is challenged by drug resistance, which remains a major obstacle to the successful treatment of cancer. Substantial research efforts have revealed that drug resistance arises from a broad range of mechanisms, such as, drug efflux, drug target mutations and engagement of alternative survival pathways (1). Recently, it was reported that drug resistance is accompanied by epithelial-mesenchymal transition (EMT), a process whereby epithelial cells lose polarity, and the ability to adhere to other cells and acquire mesenchymal properties (2-4). Sommers et al provided the first evidences of a link between drug resistance and EMT by revealing loss of epithelial markers and the acquisition of vimentin expression in adriamycin-resistant MCF-7 cells and vinblastine-resistant ZR-75-B human breast cancer cells (5). Since then, several studies have reported that cancer cells exposed to chemotherapeutic agents exhibit the EMT phenotype and that after undergoing EMT, cells possess invasive and metastatic properties in diverse cancers including breast $(5-7)$, gastric $(8,9)$ and colon cancer $(10)$.

Since it has been increasingly demonstrated that EMT plays an important role in drug resistance and metastasis, novel therapeutic strategies targeting EMT have been explored in order to overcome drug resistance. Several small molecules including the antibiotic salinomycin (11), the antiviral drug zidovudine $(12)$, and the antidiabetic drug metformin $(13,14)$ have been shown to reverse the process of EMT. In addition, curcumin, an active ingredient in curry, has been revealed to suppress doxorubicin (DOX)-induced EMT by inhibiting transforming grow factor- $\beta$ (TGF- $\beta$ ) and PI3K/AKT signaling pathways in breast cancer cells (15).

Deep-sea water (DSW) is defined as sea water obtained from a depth of more than 200 meters. DSW is rich in minerals, including calcium $(\mathrm{Ca})$, magnesium $(\mathrm{Mg})$, potassium $(\mathrm{K})$, sodium (Na) and zinc (Zn) (16), but particularly, magnesium and calcium. The concentration of calcium is $\sim 100 \mathrm{mg} / \mathrm{l}$ in 1,500 hardness DSW, while the amount of magnesium is $300 \mathrm{mg} / \mathrm{l}$. DSW has been shown to improve blood cholesterol 
and prevent obesity and atherosclerosis (17-19). Previously, we revealed that DSW decreased cancer cell metastatic potential by decreasing the expression of TGF- $\beta$, Wnt3a, Wnt5a, urokinase plasminogen activator (uPA), and matrix metalloproteinase-9 (MMP-9) $(20,21)$. Although the precise mechanisms mediating the antimetastatic effects of DSW have not been clarified yet, studies revealing that magnesium and/or calcium deficiencies are associated with cancer risk and metastasis (22-25) suggest that magnesium and calcium may play important mediatory roles in the antimetastatic effects of DSW. In addition, in our previous study, it was also observed that DSW provides a cardioprotective effect against DOX-induced cardiotoxicity, which compromised clinical use of DOX (26). Thus, in the present study, we further evaluated whether DSW has the potential to abolish the side-effects of DOX by targeting EMT in MCF-7 human breast cancer cells.

\section{Materials and methods}

Cell culture. MCF-7 human breast cancer cells were purchased from the Korean Cell Line Bank (Seoul, Korea). The cells were cultured in Dulbecco's modified Eagle's medium (DMEM) (Welgene, Daegu, Korea) containing 10\% fetal bovine serum (FBS) (Invitrogen, Carlsbad, CA, USA), $1 \%$ antibiotic-antimycotic solution (Welgene), and $10 \mu \mathrm{g} / \mathrm{ml}$ insulin (Welgene) at $37^{\circ} \mathrm{C}$ in a $5 \% \mathrm{CO}_{2}$ incubator.

Preparation of DSW. DSW was supplied by the Marine Deep Ocean Water Application Research Center at the Korean Institute of Ocean Science and Technology (Goseong, Korea). DSW was taken $6.7 \mathrm{~km}$ off the Goseong (Gangwon-Do, Korea) coast at a depth of 500 meters. Samples were microfiltered, subjected to reverse osmosis, and concentrated by electrodialysis to obtain desalinated water (hardness 0 ) and 4,000 hardness DSW. To prepare DSW containing media, DMEM powder (Sigma, St. Louis, MO, USA) was dissolved in hardness 4,000 DSW and diluted with desalinated DSW (hardness 0) to obtain hardness 1,500 DSW media. Further serial dilutions were performed to achieve hardness of 500 and 1,000 from 1,500 hardness DSW using desalinated media (hardness 0 ). The ratio of magnesium to calcium presented in DSW was 3:1. Hardness was calculated using the following equation:

Hardness of DSW $(\mathrm{mg} / \mathrm{l})=\mathrm{Mg}(\mathrm{mg} / \mathrm{l}) \times 4.1+\mathrm{Ca}(\mathrm{mg} / \mathrm{l}) \times 2.5$

Cell treatment. MCF-7 cells were treated with $0.5 \mu \mathrm{M}$ DOX (Sigma) or DSW of various hardness $(500,1,000$ and 1,500) and further cultured for $72 \mathrm{~h}$. The cells were harvested for RNA isolation or the preparation of protein lysates. To inhibit the ERK1/2, p38 or PI3K/AKT signaling pathways, the cells were pretreated with $10 \mu \mathrm{M}$ U0126 (a MEK1/2 inhibitor), SB203580 (a p38 inhibitor) or LY294002 (a PI3K/AKT inhibitor) (all from LC Laboratories, Woburn, MA, USA) for $24 \mathrm{~h}$, and then treated with $0.5 \mu \mathrm{M}$ DOX for $72 \mathrm{~h}$.

Cell viability assay. MCF-7 cells were seeded into 96-well plates at $37^{\circ} \mathrm{C}$ and incubated for $24 \mathrm{~h}$. To assess the antitumor effects of DOX or DSW, the cells were treated with DOX or DSW and cultured for an additional 24,48 or $72 \mathrm{~h}$. To study the combined effects of DOX and DSW, the cells were treated with DSW (hardness 500-1,500) in the presence of $0.3 \mu \mathrm{M}$ DOX. Cell viabilities were assessed using 3-(4,5-dimethyl2-thiazolyl)-2,5-diphenyl-2H-tetrazolium bromide (MTT) reagent (Sigma). Absorbances were assessed at $570 \mathrm{~nm}$ using a Multi-Detection Microplate Reader (Molecular Devices, Sunnyvale, CA, USA).

Transwell migration assay. Transwell chambers (Corning Inc., Corning, NY, USA) with 8- $\mu \mathrm{m}$ pore polycarbonate filters coated with Matrigel matrix (BD Biosciences, Bedford, MA, USA) were used for the assay. $3 \times 10^{4}$ cells/well were seeded on the upper chamber of 24-well plates, which were coated with Matrigel 1:20 for $1 \mathrm{~h}$. After $24 \mathrm{~h}$ of culture, DMEM containing $0.3 \mu \mathrm{M}$ DOX and 2\% FBS was placed in the upper chamber and media containing $10 \%$ FBS was placed in the lower chamber and cells were cultured for an additional $72 \mathrm{~h}$. The cells were then fixed with $100 \%$ methanol for $10 \mathrm{~min}$ and stained with hematoxylin and eosin (Sigma). Non-invasive cells were removed with a cotton swab and the membranes were mounted onto glass slides using mounting solution (Sigma). Membranes were placed on a microscope slide to take optical microscopic images.

Wound-healing assay. $4 \times 10^{5}$ MCF-7 cells/well were seeded on collagen-coated $(20 \mu \mathrm{g} / \mathrm{ml})$ (Corning Inc.) 6-well plates and incubated at $37^{\circ} \mathrm{C}$. After growing for $48 \mathrm{~h}$ to reach $100 \%$ confluence, the cell layers were scratched with a $200 \mu \mathrm{l}$ yellow pipette tip to create wounds and washed with PBS to remove cell debris. The cells were then treated with $0.3 \mu \mathrm{M}$ DOX or DSW of various hardness, and optical images were captured at 0 and $72 \mathrm{~h}$ after wounding.

$R N A$ isolation and reverse transcriptase-polymerase chain reaction (RT-PCR). Cells were grown and treated in 6-well plates as described above. Total RNA was extracted using the easy-BLUE ${ }^{\mathrm{TM}}$ Total RNA Extraction kit (iNtRON Biotechnology Inc., Sungnam, Korea). RT-PCR was performed using $1 \mu \mathrm{g}$ of total RNA using the Avian Myeloblastosis Virus RNA PCR kit version 3.0 (Takara Bio, Inc., Shiga, Japan). DNA amplicons were subjected to agarose gel electrophoresis containing $0.5 \mu \mathrm{g} / \mathrm{ml}$ of ethidium bromide (EtBr), and visualized using an UV transluminometer (CoreBio System, Seoul, Korea). Primer sequences of the target genes are presented in Table I.

Western blotting. Cells were grown and treated in 6-well plates as aforementioned. The cells were lysed with RIPA buffer $(150 \mathrm{mM} \mathrm{NaCl}, 1 \%$ Triton $\mathrm{X}-100,1 \%$ sodium deoxycholate, $0.1 \%$ SDS, $50 \mathrm{mM}$ Tris- $\mathrm{HCl} \mathrm{pH} 7.5$ and $2 \mathrm{mM}$ EDTA) including a phosphatase and protease inhibitor cocktail (GenDEPOT, Barker, TX, USA). Lysates were centrifuged at $13,000 \mathrm{rpm}$ for $20 \mathrm{~min}$ to clear debris and protein concentrations were determined using bicinchoninic acid reagent (Sigma). Proteins $(20 \mu \mathrm{g})$ were separated by SDS-PAGE (8-12\% gels) and transferred to polyvinylidene fluoride (PVDF) membranes at $100 \mathrm{~V}$ for $40 \mathrm{~min}$. The membranes were blocked in 5\% skim milk in TBS-Tween (50 mM Tris-HCl, $150 \mathrm{mM} \mathrm{NaCl}$ and $0.1 \%$ Tween-20) for $1 \mathrm{~h}$ at room temperature and incubated with the following primary 


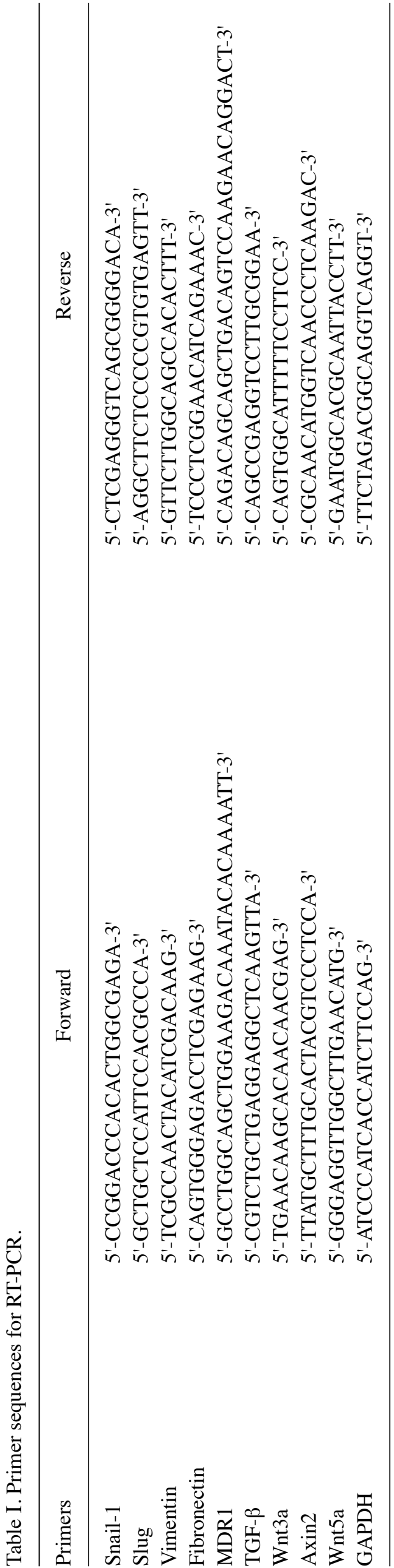

antibodies: anti-rabbit phospho-extracellular signal-regulated kinase 1/2 (p-ERK1/2), total-ERK1/2, phospho-p38 (p-p38), total-p38, phospho-protein kinase B (p-AKT), total-AKT, phospho-GSK3 $\beta$, glyceraldehyde-3-phosphate dehydrogenase (GAPDH) (Cell Signaling Technology, Inc., Beverly, MA, USA) and $\beta$-actin (Santa Cruz Biotechnology, Inc., Santa Cruz, CA, USA), overnight at $4^{\circ} \mathrm{C}$. Blots were then incubated with HRP-conjugated secondary anti-rabbit and -mouse antibodies (Santa Cruz Biotechnology Inc.), diluted 1:3,000 for $1 \mathrm{~h}$ at room temperature and developed by Luminescent Image Analyzer LAS-4000 (Fujifilm, Tokyo, Japan).

Statistical analysis. Statistical analysis was conducted using the Student's t-test. All experiments were conducted in triplicate and the results are presented as the means \pm SDs. P-values of $<0.05$ were considered as statistically significant.

\section{Results}

DOX induces EMT, and thus enhances human breast cancer cell motility. To assess the antitumor effects of DOX, we first evaluated the viabilities of MCF-7 human breast cancer cells treated with different concentrations of DOX for 24, 48 or 72 h. As shown in Fig. 1A, treatment with DOX significantly and dose-dependently decreased cell viability. Despite, its therapeutic effects, we observed that DOX-treatment caused cells to become spindle-shaped and to detach from each other (Fig. 1B). Since these morphological changes were reminiscent of the EMT phenotype, we evaluated the mRNA expression of EMT markers in DOX-treated cells. DOX increased the expression of mesenchymal markers, vimentin and fibronectin. Furthermore, the expression of mesenchymal transcription factors, Snail-1 and Slug, were also enhanced by DOX (Fig. 1C), suggesting that DOX induced EMT. Since EMT is associated with cell motility, we assessed the effects of DOX on the migration and invasion of MCF-7 cells. The migratory ability was examined using in vitro wound-healing assay. After creating uniform wounds with a $200 \mu \mathrm{l}$ pipette tip, the ability of the cells to migrate and close the wound gap were assessed. MCF-7 cells are weakly invasive in vitro, but cells treated with $0.3 \mu \mathrm{M}$ DOX for $72 \mathrm{~h}$ were found to rapidly close wounds (Fig. 1D). We also performed Transwell migration assay. Treatment of MCF-7 cells with $0.3 \mu \mathrm{M}$ DOX for $72 \mathrm{~h}$ in the upper chamber stimulated cells to migrate through the microporous membrane (Fig. 1E). Collectively, our data revealed that DOX induced EMT, and thus, enhanced the migratory ability of the cells.

DSW increases the antitumor effects of DOX by inhibiting $M D R 1$. We first assessed whether DSW itself has anticancer effects on MCF-7 human breast cancer cells. After MCF-7 cells were treated with DSW of varying hardness for 24 or $48 \mathrm{~h}$, we assessed cell viabilities using an MTT assay. As shown in Fig. 2A, cell proliferation was not affected by DSW treatment even when cells were treated with 1,500 hardness DSW for $48 \mathrm{~h}$ (Fig. 2A). However, we found that DSW enhanced the antitumor effect of DOX (Fig. 2B). The cells were treated with DSW of varying hardness in the presence of $0.3 \mu \mathrm{M}$ DOX and further incubated for another 24,48 or $72 \mathrm{~h}$ before assessing cell viability by MTT assay. Notably, 

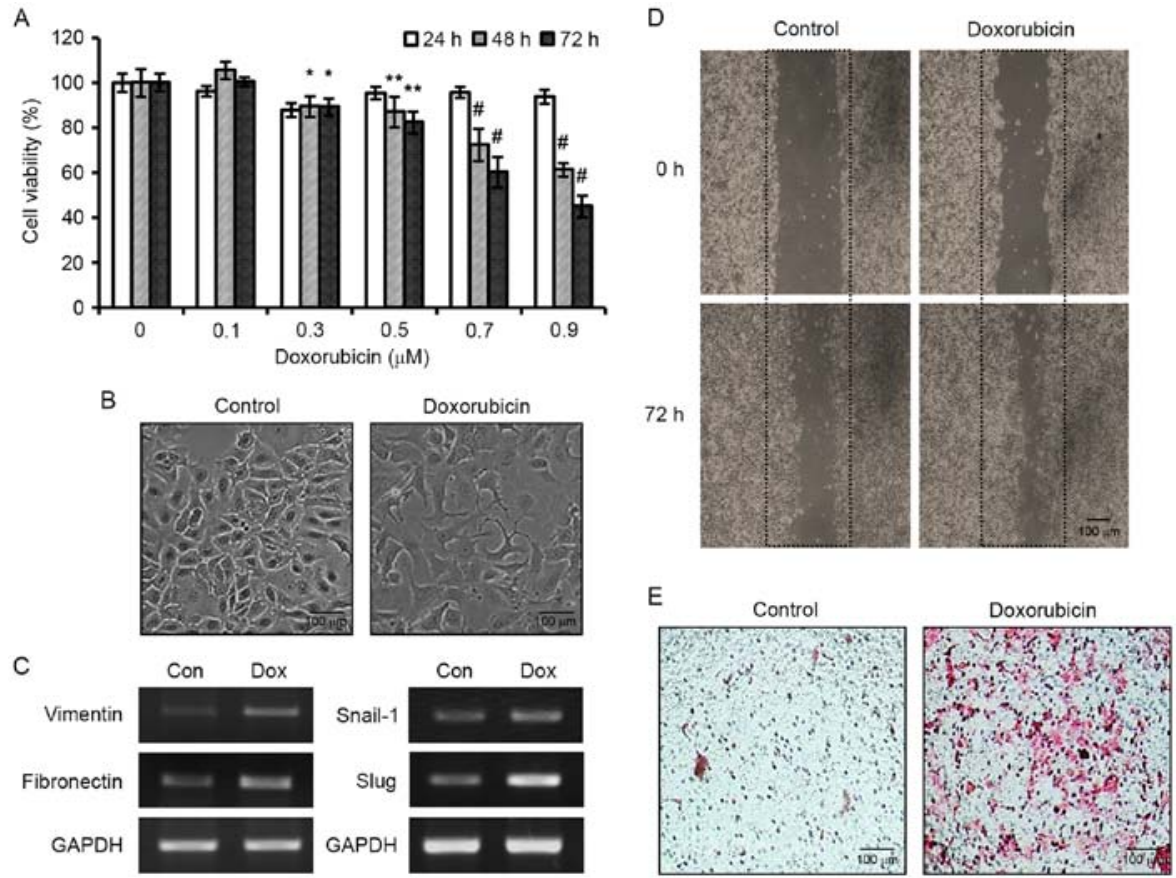

Figure 1. Stimulation of EMT and enhanced motility of MCF-7 human breast cancer cells by DOX. (A) Cells were treated with various concentrations of DOX for 24, 48 or $72 \mathrm{~h}$, and cell viabilities were assessed by MTT. Results are expressed as the means \pm SDs of three independent experiments performed in triplicate; ${ }^{*} \mathrm{P}<0.05,{ }^{* *} \mathrm{P}<0.01$ and ${ }^{*} \mathrm{P}<0.001$ compared to the control. (B) Morphological images of MCF-7 cells exposed to DOX for $72 \mathrm{~h}$. Scale bar, $100 \mu \mathrm{m}$. (C) Effects of DOX on the mRNA expression of the mesenchymal markers, vimentin and fibronectin, and on the transcription factors, Snail-1 and Slug. (D) Photomicrographs of DOX-induced wound-healing in MCF-7 cells at 0 and $72 \mathrm{~h}$ after wounding. (E) Photomicrographs of Transwell migration assay. Cells were treated with $0.3 \mu \mathrm{M}$ DOX for $72 \mathrm{~h}$ and the cells that migrated through the membrane were stained with H\&E. Scale bar, $100 \mu \mathrm{m}$. EMT, epithelial-mesenchymal transition; DOX, doxorubicin.
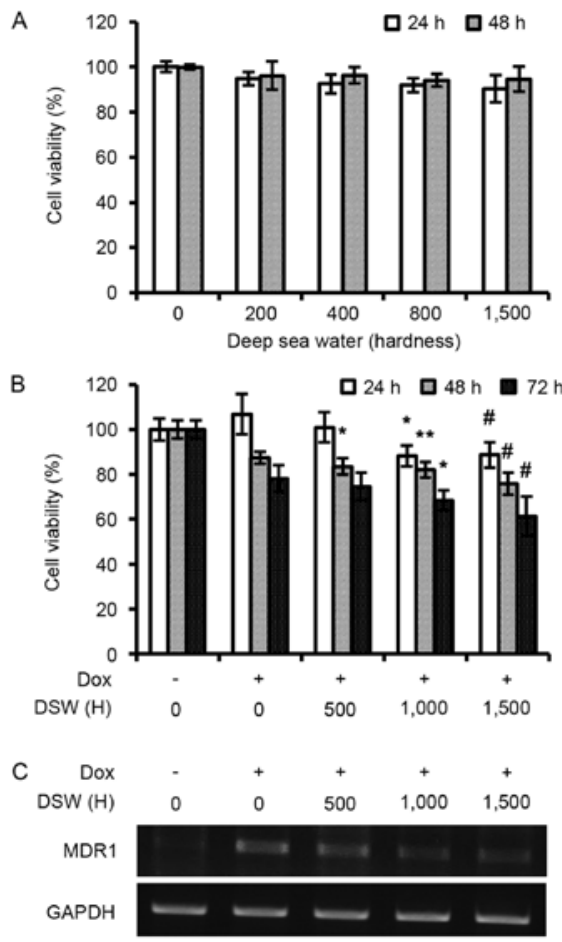

Figure 2. DSW mildly enhances antitumor effects of DOX by inhibiting MDR1. (A) DSW did not inhibit the viability of MCF-7 cells at up to a hardness $(\mathrm{H})$ of 1,500 . Results are the means \pm SDs of three independent experiments performed in triplicate. (B) DSW mildly enhanced the antitumor effect of DOX on MCF-7 cells. Results are the means \pm SDs of three independent experiments performed in triplicate; ${ }^{*} \mathrm{P}<0.05,{ }^{* *} \mathrm{P}<0.01$ and ${ }^{\text {"P }}<0.001$ vs. DOX treatment only. (C) The inhibitory effect of DSW on the mRNA expression of MDR1. DSW, deep-sea water; DOX, doxorubicin; MDR1, multidrug resistance 1. mildly enhanced antitumor effects of DOX were observed in a hardness-dependent manner; a decrease in cell viabilities of $\sim 20 \%$ was found after treatment with DSW of hardness 1,500 for $72 \mathrm{~h}$ (Fig. 2B). To understand the underlying mechanism of this enhanced antitumor effect of DOX by DSW, we examined the mRNA expression of the ATP-binding cassette (ABC) drug transporter, multidrug resistance 1 (MDR1). As shown in Fig. 2C, the expression of MDR1 was significantly induced by DOX, however co-treatment with DSW suppressed this DOX-induced MDR1 expression, suggesting that DSW enhanced the efficacy of DOX by inhibiting the expression of MDR1.

DSW suppresses DOX-induced EMT and in vitro cancer cell migration. To investigate the effect of DSW on DOX-induced EMT, we evaluated the expression of EMT markers in mRNA expression after cells were treated with $0.5 \mu \mathrm{M}$ DOX or in combination with varying DSW hardness for three days. As shown in Fig. 3A, Snail-1 and Slug were induced by DOX however treatment with DSW significantly decreased their expression. Similar inhibitory effects of DSW were observed in DOX-induced expression of vimentin and fibronectin (Fig. 3A), suggesting that DSW suppresses DOX-induced EMT. Consequently, co-treatment of the cells with varying hardness of DSW for up to $72 \mathrm{~h}$ significantly and hardness-dependently decreased DOX-induced migration vs. DOX-treated control cells in the wound-healing assay (Fig. 3B).

DSW suppresses TGF- $\beta$ and Wnt signaling pathways. The TGF- $\beta$ signaling pathway is well known to induce EMT (27). 
A

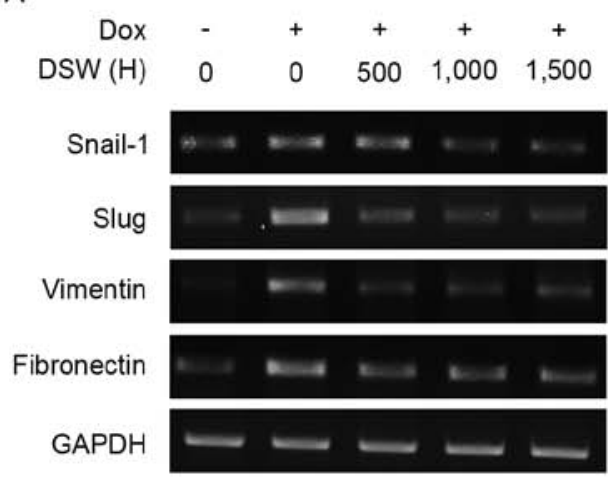

B

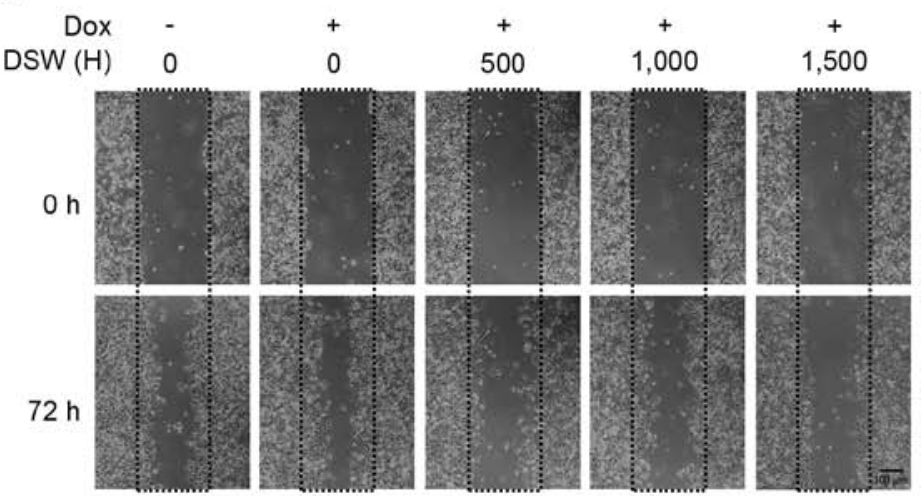

Figure 3. The inhibitory effects of DSW on DOX-induced EMT and in vitro cancer cell migration. The inhibitory effects of DSW on the mRNA expression of (A) the transcription factors, Snail-1 and Slug, and the mesenchymal markers, vimentin and fibronectin. (B) Photomicrographs of in vitro healing at 0 and $72 \mathrm{~h}$ after wounding. Cells were co-treated with DSW at varying hardness in the presence of $0.3 \mu \mathrm{M}$ DOX for $72 \mathrm{~h}$ after wounding. Scale bar, $100 \mu \mathrm{m}$. DSW, deep-sea water; DOX, doxorubicin; EMT, epithelial-mesenchymal transition.

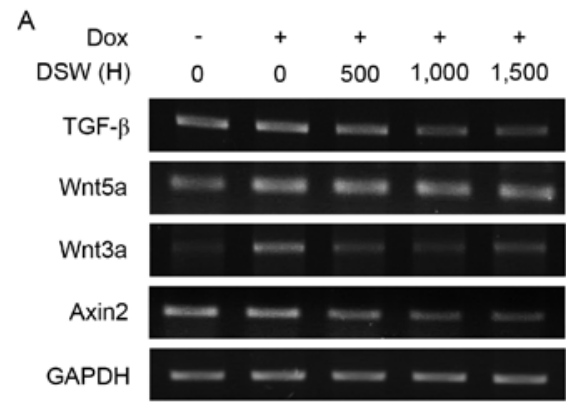

B

\begin{tabular}{|c|c|c|c|c|c|}
\hline Dox & - & + & + & + & + \\
\hline DSW $(H)$ & 0 & 0 & 500 & 1,000 & 1,500 \\
\hline \multicolumn{6}{|l|}{ p-GSK3 $\beta$} \\
\hline$\beta$-actin & & & & & \\
\hline
\end{tabular}

Figure 4. DSW suppresses TGF- $\beta$ and Wnt signaling pathways. (A) The inhibitory effects of DSW on the mRNA expression of TGF- $\beta$. DSW did not alter the expression of non-canonical Wnt ligand, Wnt5a, but suppressed canonical Wnt ligand, Wnt3a and its target gene, Axin2. (B) The western blot analysis revealed that the DOX-induced expression of phospho-GSK3 $\beta$ was inhibited by DSW. DSW, deep-sea water; TGF- $\beta$, transforming grow factor- $\beta$; DOX, doxorubicin; p-GSK3 $\beta$, phospho-GSK3 $\beta$.

Bandyopadhyay et al revealed that DOX activated the Smad-dependent TGF- $\beta$ signaling pathway to induce EMT, consequently promoting invasion in murine $4 \mathrm{~T} 1$ breast cancer cells (6). In addition, DOX resistance in HCT116 human colon cancer cells promoted EMT by upregulating TGF- $\beta$ (10). Thus, we explored the effect of DSW on TGF- $\beta$ signaling pathways. After cells were treated with $0.5 \mu \mathrm{M}$ DOX or in combination with varying hardness of DSW for three days, we assessed the mRNA expression of TGF- $\beta$. As shown in Fig. 4A, treatment with DSW significantly decreased the mRNA expression of TGF- $\beta$, though DOX mildly stimulated its induction. Since the canonical TGF- $\beta$ signaling pathway depends on activation of the Smad family (27), particularly Smad2 and Smad 3, we tried to assess the level of phosphorylated $\mathrm{Smad} 2 / 3$ in cells exposed to DOX or DSW. However, we were not able to detect the activated $\mathrm{Smad} 2 / 3$ expression in $\mathrm{MCF}-7$ cells exposed to DOX, as well as the endogenous level of Smad2/3 expression in untreated cells (data not shown). Thus, we were not able to clarify the role of the Smad-dependent TGF- $\beta$ signaling pathway in mediating the inhibitory effects of DSW on DOX-induced EMT in the present study. Since recent studies revealed that TGF- $\beta$, directly upregulated non-canonical Wnt ligand, Wnt5a expression through the Smad complex (28), we also tried to evaluate the mRNA expression of Wnt5a. Although the expression of Wnt5a was induced by stimulation of the cells with DOX, this DOX-induced Wnt5a expression was not decreased by treatment with DSW (Fig. 4A), implying that the inhibitory effects of DSW on DOX-induced EMT are independent of the non-canonical Wnt signaling pathway and possibly independent of the Smad-dependent TGF- $\beta$ signaling pathway.

Wnt5a is a non-canonical signaling member of the Wnt family, and its activation is independent of $\beta$-catenin. In contrast, activation of the canonical Wnt signaling pathway depends on $\beta$-catenin (29). Upon binding of canonical Wnt signaling members, such as Wnt1 and Wnt3a, to frizzled (FZD) and low-density lipoprotein receptor-related protein $5 / 6$ (LRP 5/6), GSK3 $\beta$ is phosphorylated to its inactive form, and thus functional $\beta$-catenin accumulates in the cytosol and is further transported into the nucleus to activate target genes, such as, Axin2 and Snail-1. Since the Wnt signaling pathway is another signaling pathway that promotes EMT in coordination with the TGF- $\beta$ signaling pathway $(30,31)$, we evaluated the mRNA expression of Wnt3a and its target gene, Axin2. Non-treated control MCF-7 cells exhibited barely detectable levels of Wnt3a mRNA, while DOX-treated cells exhibited significant Wnt3a expression. However, co-treatment with DSW efficiently suppressed the expression of Wnt3a, and its target gene, Axin2 (Fig. 4A). Moreover, we found that the inactive form of GSK $3 \beta$ was decreased by DSW co-treatment (Fig. 4B), which suggested that the inhibitory effects of DSW on the canonical Wnt signaling pathway are involved in targeting EMT.

The inhibitory effects of DSW on DOX-induced EMT are mediated by the inhibition of the ERK1/2, p38 MAPK and $P I 3 K / A K T$ signaling pathways. TGF- $\beta$ activates various kinase pathways, including extracellular signal-regulated 

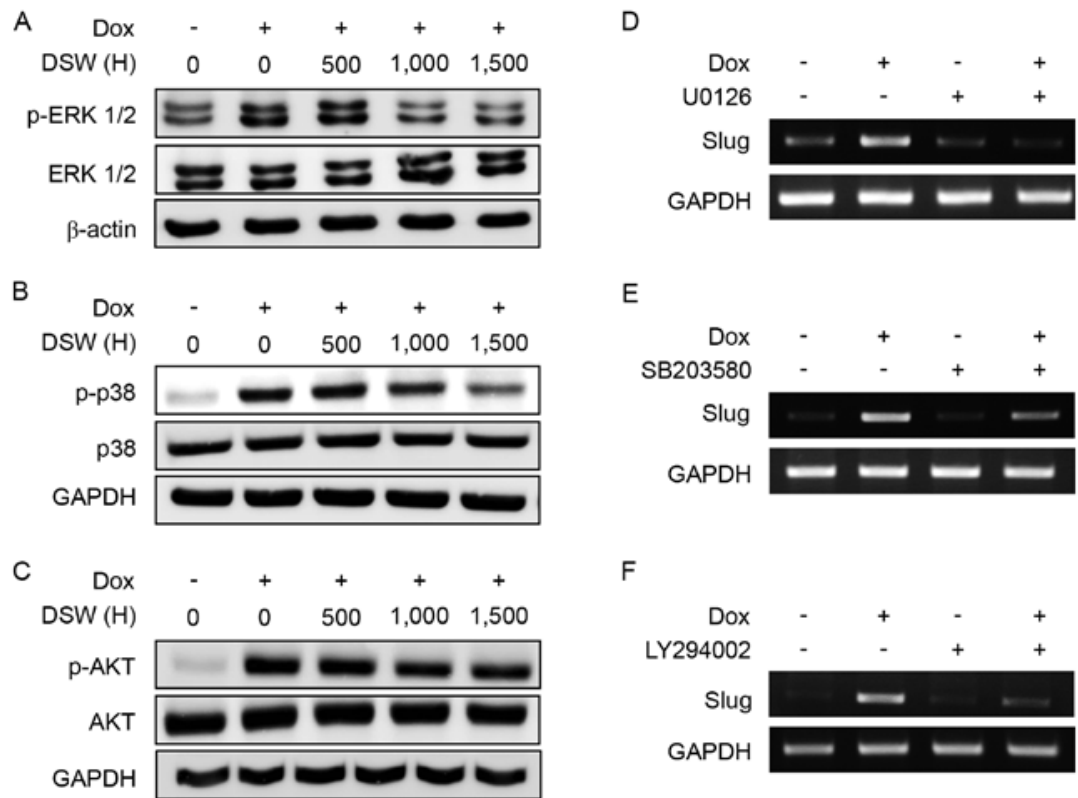

Figure 5. Inhibitory effects of DSW on DOX-induced EMT are mediated through inhibition of the ERK1/2, p38 and AKT signaling pathways. The inhibitory effects of DSW on DOX-induced phosphorylation of (A) ERK1/2, (B) p38 and (C) AKT. The involvement of the ERK1/2, p38 and AKT signaling pathways in DOX-induced EMT was confirmed by blocking each pathway with a specific inhibitor. The effects of (D) U0126 (a MEK1/2 inhibitor), (E) SB203580 (a p38 inhibitor) and (F) LY294002 (a PI3K/AKT inhibitor) on Slug expression. DSW, deep-sea water; DOX, doxorubicin; EMT, epithelial-mesenchymal transition; ERK1/2, extracellular signal-regulated kinase 1/2; AKT, protein kinase B.

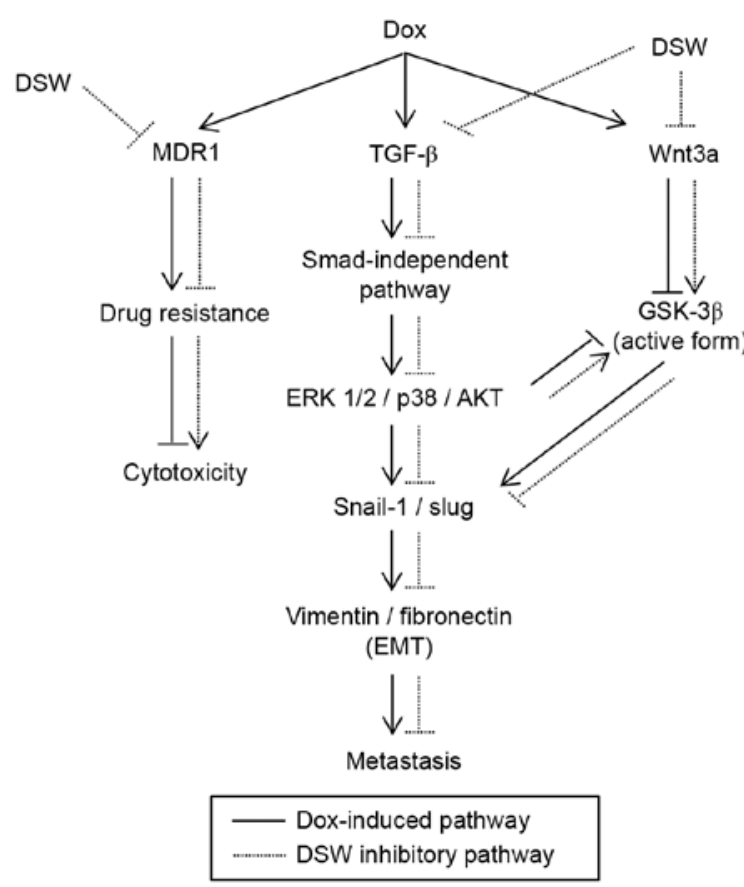

Figure 6. The proposed action mechanism responsible for the suppressive effects of DSW on DOX-induced EMT and on the antitumor effects of DOX. DSW inhibited the Smad-independent and the Wnt canonical signaling pathway to prevent the process of EMT. Increase in the active form of GSK3 $\beta$ by DSW may have inhibited the expressions of Slug or Snail-1 directly or through the Smad-independent signaling pathways. In addition, DSW augmented the antitumor effects of DOX by inhibiting MDR1. DSW, deep-sea water; DOX, doxorubicin; EMT, epithelial-mesenchymal transition; MDR1, multidrug resistance 1 .

kinase 1/2 (ERK1/2), PI3K/AKT and p38 mitogen-activated protein kinase (MAPK) through a Smad-independent signaling pathway (27), and these pathways are implicated in the activation of EMT. Since DSW efficiently suppressed the expression of TGF- $\beta$, we further analyzed whether the inhibitory effect of DSW on TGF- $\beta$ expression subsequently affected the ERK1/2, PI3K/AKT and p38 MAP kinase signaling pathways. After cells were treated with $0.5 \mu \mathrm{M}$ DOX or in combination with varying hardness of DSW for three days, western blot analysis was performed. DOX significantly induced the phosphorylation of ERK1/2, but co-treatment with DSW efficiently decreased this phosphorylation (Fig. 5A). Similarly, the phosphorylation of p38 and AKT were also found to be induced in DOX-treated MCF-7 cells, but DSW co-treatment significantly inhibited the phosphorylation of p38 and AKT (Fig. 5B and C). To further confirm the role of the PI3K/AKT and MAP kinase signaling pathways in DOX-induced EMT, we blocked the ERK1/2, p38 and PI3K/AKT signaling pathways using U0126, SB203580 and LY294002, respectively. Cells were treated with $10 \mu \mathrm{M}$ U0126, $10 \mu \mathrm{M}$ SB203580 or $10 \mu \mathrm{M} \mathrm{LY} 294002$ for $24 \mathrm{~h}$ prior to the addition of $0.5 \mu \mathrm{M}$ DOX, and then incubated for another $72 \mathrm{~h}$. Notably, Slug upregulation in DOX-treated cells was efficiently prevented by blocking the ERK1/2 (Fig. 5D), p38 (Fig. 5E) or PI3K/AKT (Fig. 5F) signaling pathways, which suggested that the MAPK and PI3K/AKT signaling pathways played a critical role in DOX-induced EMT. Collectively, our data revealed that the inhibitory effects of DSW on DOX-induced EMT are mediated through the inhibition of the ERK1/2, p38 and AKT signaling pathways.

\section{Discussion}

In the present study, we have evaluated the potential health benefit of DSW on DOX-induced EMT in MCF-7 human breast cancer cells. Our data revealed that MCF-7 cells treated with DOX displayed characteristics of EMT by exhibiting 
the acquisition of mesenchymal markers, vimentin and fibronectin, and the EMT-related transcription factors, Slug and Snail-1 in their mRNA expression. In addition, we observed that DOX stimulated the migratory ability of MCF-7 cells in an in vitro wound-healing assay. It was consistent with other studies which revealed that chemotherapy agents, such as, doxorubicin and paclitaxel, promoted EMT of treated cancer cells, and cells that underwent EMT exhibited the enhanced properties of migration and invasion (5-10).

Cooperation of signaling pathways, such as, TGF- $\beta$, Sonic Hedgehog ( $\mathrm{SHH})$ and Wnt signaling pathways, is known to promote EMT $(30,31)$. Particularly, the TGF- $\beta$ signaling pathway is the most well-established pathway that induces EMT and tumor metastasis (27). The canonical TGF- $\beta$ signaling pathway is mediated by activation of the Smad family. Upon ligand binding, phosphorylation of TGF- $\beta$ receptor I (TGF- $\beta$ RI) by TGF- $\beta$ RII results in the recruitment of Smad 2 and Smad3, which are then transported from the cytosol to the nucleus after complex formation with the coactivator Smad4. In the nucleus, the Smad complex binds to regulatory elements to induce the transcription of target genes associated with EMT, such as, Snail and Slug (27). Since we were not able to detect activated Smad2 or Smad3 expression in MCF-7 cells exposed to DOX, or endogenous Smad2/3 in untreated cells (data not shown), the role of the Smad-dependent TGF- $\beta$ signaling pathway in DOX-induced EMT was not clarified in the present study. However, Chen et al suggested that the Smad-dependent TGF- $\beta$ signaling pathway may play a minor role in DOX-induced EMT since a specific inhibitor of TGF- $\beta$ receptor kinase, SB431542, was not able to abrogate DOX-induced E-cadherin downregulation and altered Snail expression in BT-20 breast cancer cells (15).

In addition to Smad-dependent mechanisms, TGF $\beta$ induced EMT is also mediated through Smad-independent mechanisms (27,31). Particularly, the ERK MAPK, p38 MAPK and PI3K/AKT signaling pathways have been linked to TGF $\beta$-induced EMT (27,32). Activation of ERK1/2 in response of TGF- $\beta$ is initiated by Ras, leading to the activation of Raf and MEK1/2 kinases. Increased Ras-ERK MAP kinase signaling then results in the downregulation of E-cadherin expression, whereas blocking the kinase function of MEK1/2 inhibits TGF $\beta$ induced EMT (33-35). TGF- $\beta$ also induces the activation of $\mathrm{p} 38$ MAP kinase $(36,37)$. The interaction between TNF receptorassociated factor 6 (TRAF6) and TGF- $\beta$ RI causes the activation of TGF $\beta$-activated kinase 1 (TAK1) and leads to the activation of p38 MAP kinase. Furthermore, blocking the activation of p38 MAP kinase prevents TGF $\beta$-induced EMT, which suggests that p38 MAP kinase plays a role in TGF $\beta$-induced EMT $(36,37)$. TGF- $\beta$ activates PI3 kinase directly through its own receptors $(38,39)$. Upon binding of the regulatory subunit of PI3 kinase to TGF- $\beta$ RI and TGF- $\beta$ RII, AKT is activated, resulting in the activation of mTOR/S6 kinase. Notably, a dominant negative form of AKT was found to inhibit TGF $\beta$-induced EMT $(38,40)$. In the present study we found that the Smad-independent TGF- $\beta$ signaling pathways were involved in DOX-induced EMT in MCF-7 cells. Induction of the phosphorylation of ERK1/2, p38 and AKT were observed in cells treated with DOX. Since the treatment of cells with selective inhibitors of each pathway markedly prevented the process of EMT, our data revealed that the ERK1/2, p38 and AKT signaling pathways are involved in
DOX-induced EMT. However, DSW efficiently inhibited the phosphorylation of ERK1/2, p38 and AKT. Consequently, the expressions of mesenchymal markers, vimentin and fibronectin, and EMT-related transcription factors, Slug and Snail-1 were decreased by DSW. Moreover, DSW significantly suppressed the DOX-induced increase in the migratory ability of MCF-7 cells as determined by the wound-healing assay. Collectively, our data revealed that DSW targeted these Smad-independent TGF- $\beta$ signaling pathways to prevent DOX-induced EMT in MCF-7 cells.

The Wnt signaling pathway is another signaling pathway that promotes EMT in coordination with the TGF- $\beta$ signaling pathway (29-31). Without Wnt signals, the tumor suppressor, GSK $3 \beta$ exists in its active form, which phosphorylates $\beta$-catenin for degradation. When the canonical Wnt signaling pathway is activated by binding canonical Wnt signaling members, such as, Wnt1 and Wnt3a, to FZD and LRP 5/6, GSK $3 \beta$ is phosphorylated, and thus inactivated. Functional $\beta$-catenin is then accumulated in the cytosol and is further transported into the nucleus to activate target genes, such as, Axin 2 and Snail-1. Since it is established that TGF- $\beta$ can also inactivate GSK3 $\beta$ by activating Smad-independent pathways, including the ERK MAPK (41), p38 MAPK (42) and PI3K/AKT (43) signaling pathways, GSK3 $\beta$ is a major converging element between the Wnt and TGF- $\beta$ signaling pathways. Furthermore, inactivation of GSK3 $\beta$ can increase Snail-1 expression directly by transporting Snail-1 from the nucleus to the cytosol for degradation (44). We previously reported that DSW inhibits the Wnt signaling pathway, which mediates cell migration and invasion in coordination with the TGF- $\beta$ signaling pathway (20). In the present study, we confirmed that DSW efficiently suppressed the expression of canonical Wnt signaling ligand, Wnt3a, and its target gene, Axin2. Furthermore, we found that the inactive form of GSK $3 \beta$ was decreased by DSW, which implies that increasing the active form of GSK $3 \beta$ by DSW may inhibit the expression of Slug or Snail-1 directly or through the Smad-independent signaling pathways (Fig. 6).

Minerals are essential for all living organisms and recent studies revealed that the intake of certain minerals decreases the incidence of cancer. Wark et al reported that a higher intake of dietary magnesium was associated with lower risk of colorectal tumors (45). Furthermore, decreased serum levels of magnesium are frequently observed in patients with tumors $(22,46)$. Zinc is an essential mineral that acts as a co-factor for diverse enzymes. Notably, zinc differentially modulated DNA damage in normal and cancer cells. Zinc exhibited a protective action against DNA damage induced by hydrogen peroxide in normal cells, whereas zinc inhibited the DNA repair for hydrogen peroxide-induced DNA damage in cancer cells (47). Fong et al also reported the role of zinc, demonstrating that dietary zinc deficiency led to an increased tumor incidence in mice (48). Epidemiologic studies suggest that intake of calcium appears to decrease the risk of colon cancer (25). In addition, individuals with improved calcium and vitamin D nutritional status substantially decreased all cancer risk in postmenopausal women (23). Since DSW is rich in minerals, such as, calcium, magnesium and zinc, we presumed that the combined ionic action of several minerals may play important roles in inhibiting DOX-induced EMT. 
In summary, our results revealed that DSW inhibits DOX-induced EMT without interfering with the anticancer effects of DOX. We found that DSW inhibited the Smad-independent signaling pathway and the Wnt canonical signaling pathway to prevent the process of EMT. The mechanism responsible for the DSW-mediated suppression of DOX-induced EMT was not fully elucidated in the present study and further investigation is warranted on this topic. However, this is the first study to reveal that DSW has a substantial inhibitory effect on DOX-induced EMT. Collectively, our findings suggest that DSW may improve the clinical use of DOX by suppressing its side-effects by targeting EMT in MCF-7 human breast cancer cells.

\section{Acknowledgements}

The present study was supported financially by the National R\&D Project 'Development of New Application Technology for the Deep Seawater Industry' of the Korean Ministry of Oceans and Fisheries.

\section{References}

1. Garraway LA and Jänne PA: Circumventing cancer drug resistance in the era of personalized medicine. Cancer Discov 2: 214-226, 2012.

2. Hay ED: An overview of epithelio-mesenchymal transformation. Acta Anat 154: 8-20, 1995.

3. Kalluri R and Weinberg RA: The basics of epithelial-mesenchymal transition. J Clin Invest 119: 1420-1428, 2009.

4. Wang Y and Zhou BP: Epithelial-mesenchymal transition in breast cancer progression and metastasis. Chin J Cancer 30: 603-611, 2011.

5. Sommers CL, Heckford SE, Skerker JM, Worland P, Torri JA, Thompson EW, Byers SW and Gelmann EP: Loss of epithelial markers and acquisition of vimentin expression in adriamycin- and vinblastine-resistant human breast cancer cell lines. Cancer Res 52: 5190-5197, 1992.

6. Bandyopadhyay A, Wang L, Agyin J, Tang Y, Lin S, Yeh IT, De $K$ and Sun LZ: Doxorubicin in combination with a small TGF $\beta$ inhibitor: A potential novel therapy for metastatic breast cancer in mouse models. PLoS One 5: e10365, 2010.

7. Isseri OD, Kars MD, Arpaci F, Atalay C, Pak I and Gündüz U: Drug resistant MCF-7 cells exhibit epithelial-mesenchymal transition gene expression pattern. Biomed Pharmacother 65: 40-45, 2011.

8. Han R, Xiong J, Xiao R, Altaf E, Wang J, Liu Y, Xu H, Ding Q and Zhang Q: Activation of $\beta$-catenin signaling is critical for doxorubicin-induced epithelial-mesenchymal transition in BGC-823 gastric cancer cell line. Tumour Biol 34: 277-284, 2013.

9. Han RF, Ji X, Dong XG, Xiao RJ, Liu YP, Xiong J and Zhang QP: An epigenetic mechanism underlying doxorubicin induced EMT in the human BGC-823 gastric cancer cell. Asian Pac J Cancer Prev 15: 4271-4274, 2014.

10. Li J, Liu H, Yu J and Yu H: Chemoresistance to doxorubicin induces epithelial-mesenchymal transition via upregulation of transforming growth factor $\beta$ signaling in HCT116 colon cancer cells. Mol Med Rep 12: 192-198, 2015.

11. Zhou Y, Liang C, Xue F, Chen W, Zhi X, Feng X, Bai X and Liang T: Salinomycin decreases doxorubicin resistance in hepatocellular carcinoma cells by inhibiting the $\beta$-catenin/TCF complex association via FOXO3a activation. Oncotarget 6: 10350-10365, 2015.

12. Namba T, Kodama R, Moritomo S, Hoshino T and Mizushima T: Zidovudine, an anti-viral drug, resensitizes gemcitabine-resistant pancreatic cancer cells to gemcitabine by inhibition of the Akt-GSK3 $\beta$-Snail pathway. Cell Death Dis 6: e1795, 2015.

13. Vazquez-Martin A, Oliveras-Ferraros C, Cufí S, Del Barco S, Martin-Castillo B and Menendez JA: Metformin regulates breast cancer stem cell ontogeny by transcriptional regulation of the epithelial-mesenchymal transition (EMT) status. Cell Cycle 9: 3807-3814, 2010.
14. Zhao Z, Cheng X, Wang Y, Han R, Li L, Xiang T, He L, Long H, Zhu B and He Y: Metformin inhibits the IL-6-induced epithelialmesenchymal transition and lung adenocarcinoma growth and metastasis. PLoS One 9: e95884, 2014.

15. Chen WC, Lai YA, Lin YC, Ma JW, Huang LF, Yang NS, Ho CT, Kuo SC and Way TD: Curcumin suppresses doxorubicin-induced epithelial-mesenchymal transition via the inhibition of TGF- $\beta$ and PI3K/AKT signaling pathways in triple-negative breast cancer cells. J Agric Food Chem 61: 11817-11824, 2013.

16. Nakasone T and Akeda S: The application of deep sea water in japan. UJNR Technical Report 28: 69-75, 1999.

17. Hwang HS, Kim SH, Yoo YG, Chu YS, Shon YH, Nam KS and Yun JW: Inhibitory effect of deep-sea water on differentiation of 3T3-L1 adipocytes. Mar Biotechnol 11: 161-168, 2009.

18. Lee KS, Kwon YS, Kim S, Moon DS, Kim HJ and Nam KS: Regulatory mechanism of mineral-balanced deep sea water on hypocholesterolemic effects in HepG2 hepatic cells. Biomed Pharmacother 86: 405-413, 2017.

19. Radhakrishnan G, Yamamoto M, Maeda H, Nakagawa A, KatareGopalrao R, Okada H, Nishimori H, Wariishi S, Toda E, Ogawa $\mathrm{H}$, et al: Intake of dissolved organic matter from deep seawater inhibits atherosclerosis progression. Biochem Biophys Res Commun 387: 25-30, 2009.

20. Kim S, Chun SY, Lee DH, Lee KS and Nam KS: Mineralenriched deep-sea water inhibits the metastatic potential of human breast cancer cell lines. Int J Oncol 43: 1691-1700, 2013.

21. Lee KS, Lee DH, Kwon YS, Chun SY and Nam KS: Deep-sea water inhibits metastatic potential in HT-29 human colorectal adenocarcinomas via MAPK/NF-kB signaling pathway. Biotechnol Bioproc Eng 19: 733-739, 2014.

22. Kohli GS, Bhargava A, Goel H, Yadav SP, Saini AS, Singh GP and Lal H: Serum magnesium levels in patients with head and neck cancer. Magnesium 8: 77-86, 1989.

23. Lappe JM, Travers-Gustafson D, Davies KM, Recker RR and Heaney RP: Vitamin D and calcium supplementation reduces cancer risk: Results of a randomized trial. Am J Clin Nutr 85: 1586-1591, 2007.

24. Nasulewicz A, Wietrzyk J, Wolf FI, Dzimira S, Madej J, Maier JA, Rayssiguier Y, Mazur A and Opolski A: Magnesium deficiency inhibits primary tumor growth but favors metastasis in mice. Biochim Biophys Acta 1739: 26-32, 2004.

25. Wu K, Willett WC, Fuchs CS, Colditz GA and Giovannucci EL: Calcium intake and risk of colon cancer in women and men. $\mathrm{J}$ Natl Cancer Inst 94: 437-446, 2002.

26. Lee DH, Kim S and Nam KS: Protective effects of deep sea water against doxorubicin-induced cardiotoxicity in $\mathrm{H} 9 \mathrm{c} 2$ cardiac muscle cells. Int J Oncol 45: 2569-2575, 2014.

27. Xu J, Lamouille S and Derynck R: TGF- $\beta$-induced epithelial to mesenchymal transition. Cell Res 19: 156-172, 2009.

28. Katoh $\mathrm{M}$ and Katoh $\mathrm{M}$ : Transcriptional mechanisms of WNT5A based on NF- $\mathrm{KB}$, Hedgehog, TGF $\beta$, and Notch signaling cascades. Int J Mol Med 23: 763-769, 2009.

29. Howe LR and Brown AM: Wnt signaling and breast cancer. Cancer Biol Ther 3: 36-41, 2004.

30. Smith BN and Bhowmick NA: Role of EMT in metastasis and therapy resistance. J Clin Med 5: 17, 2016.

31. Zhang J, Tian XJ and Xing J: Signal transduction pathways of EMT induced by TGF- $\beta$, SHH, and WNT and their crosstalks. J Clin Med 5: 41, 2016.

32. Chen XF, Zhang HJ, Wang HB, Zhu J, Zhou WY, Zhang H, Zhao MC, Su JM, Gao W, Zhang L, et al: Transforming growth factor- $\beta 1$ induces epithelial-to-mesenchymal transition in human lung cancer cells via PI3K/Akt and MEK/Erk1/2 signaling pathways. Mol Biol Rep 39: 3549-3556, 2012.

33. Grände M, Franzen A, Karlsson JO, Ericson LE, Heldin NE and Nilsson M: Transforming growth factor- $\beta$ and epidermal growth factor synergistically stimulate epithelial to mesenchymal transition (EMT) through a MEK-dependent mechanism in primary cultured pig thyrocytes. J Cell Sci 115: 4227-4236, 2002.

34. Janda E, Lehmann K, Killisch I, Jechlinger M, Herzig M, Downward J, Beug H and Grünert S: Ras and TGF $\beta$ cooperatively regulate epithelial cell plasticity and metastasis: Dissection of Ras signaling pathways. J Cell Biol 156: 299-313, 2002.

35. Lehmann K, Janda E, Pierreux CE, Rytömaa M, Schulze A, McMahon M, Hill CS, Beug H and Downward J: Raf induces TGF $\beta$ production while blocking its apoptotic but not invasive responses: A mechanism leading to increased malignancy in epithelial cells. Genes Dev 14: 2610-2622, 2000. 
36. Bakin AV, Rinehart C, Tomlinson AK and Arteaga CL: p38 mitogen-activated protein kinase is required for TGF $\beta$-mediated fibroblastic transdifferentiation and cell migration. J Cell Sci 115: 3193-3206, 2002

37. Yu L, Hébert MC and Zhang YE: TGF- $\beta$ receptor-activated $\mathrm{p} 38$ MAP kinase mediates Smad-independent TGF- $\beta$ responses. EMBO J 21: 3749-3759, 2002.

38. Bakin AV, Tomlinson AK, Bhowmick NA, Moses HL and Arteaga CL: Phosphatidylinositol 3-kinase function is required for transforming growth factor $\beta$-mediated epithelial to mesenchymal transition and cell migration. J Biol Chem 275: 36803-36810, 2000.

39. Lien SC, Usami S, Chien S and Chiu JJ: Phosphatidylinositol 3-kinase/Akt pathway is involved in transforming growth factor- $\beta 1$-induced phenotypic modulation of $10 \mathrm{~T} 1 / 2$ cells to smooth muscle cells. Cell Signal 18: 1270-1278, 2006.

40. Kattla JJ, Carew RM, Heljic M, Godson C and Brazil DP: Protein kinase B/Akt activity is involved in renal TGF- $\beta 1$-driven epithelial-mesenchymal transition in vitro and in vivo. Am J Physiol Renal Physiol 295: F215-F225, 2008.

41. Caraci F, Gili E, Calafiore M, Failla M, La Rosa C, Crimi N, Sortino MA, Nicoletti F, Copani A and Vancheri C: TGF- $\beta 1$ targets the GSK-3 $\beta / \beta$-catenin pathway via ERK activation in the transition of human lung fibroblasts into myofibroblasts. Pharmacol Res 57: 274-282, 2008.

42. Bikkavilli RK, Feigin ME and Malbon CC: p38 mitogen-activated protein kinase regulates canonical Wnt $\beta$-catenin signaling by inactivation of GSK $3 \beta$. J Cell Sci 121: 3598-3607, 2008.
43. Zhou BP, Deng J, Xia W, Xu J, Li YM, Gunduz M and Hung MC: Dual regulation of Snail by GSK-3 $\beta$-mediated phosphorylation in control of epithelial-mesenchymal transition. Nat Cell Biol 6: 931-940, 2004

44. Yook JI, Li XY, Ota I, Hu C, Kim HS, Kim NH, Cha SY, Ryu JK, Choi YJ, Kim J, et al: A Wnt-Axin2-GSK3 $\beta$ cascade regulates Snaill activity in breast cancer cells. Nat Cell Biol 8: 1398-1406, 2006.

45. Wark PA, Lau R, Norat T and Kampman E: Magnesium intake and colorectal tumor risk: A case-control study and meta-analysis. Am J Clin Nutr 96: 622-631, 2012.

46. Sartori S, Nielsen I, Tassinari D, Mazzotta D, Vecchiatti G, Sero A and Abbasciano V: Serum and erythrocyte magnesium concentrations in solid tumours: Relationship with stage of malignancy. Magnes Res 5: 189-192, 1992.

47. Sliwinski T, Czechowska A, Kolodziejczak M, Jajte J, Wisniewska-Jarosinska $\mathrm{M}$ and Blasiak J: Zinc salts differentially modulate DNA damage in normal and cancer cells. Cell Biol Int 33: 542-547, 2009.

48. Fong LY and Magee PN: Dietary zinc deficiency enhances esophageal cell proliferation and $N$-nitrosomethylbenzylamine (NMBA)-induced esophageal tumor incidence in C57BL/6 mouse. Cancer Lett 143: 63-69, 1999. 